\title{
EDUCAÇÃO AMBIENTAL E PAPEL DA UNIVERSIDADE NA VISÃO DA UNIÃO EUROPEIA E BRASILEIRA: ABORDAGEM ANALÍTICA DE COMUNICADOS DA COMISSÃO SOBRE O PROGRAMA COMUNITÁRIO DE AÇÃO PARA O MEIO AMBIENTE
}

KIWONGHI BIZAWU

Mestre e Doutor em Direito Internacional pela Pontifícia Universidade Católica de Minas Gerais (PUC-MG), Professor de Direito Internacional na graduação e Mestrado em Direito Ambiental e Desenvolvimento Sustentável e Pró-Reitor do Programa de Pós-Graduação em Direito na Escola Superior Dom Helder Câmara em Belo Horizonte MG. Membro do Núcleo Docente Estruturante.

Maraluce Maria Custódio Mestre em Direito Constitucional pela UFMG. Mestre em Direito Ambiental pela Universidad Internacional de Andalucía (Espanha). Doutora em Geografia pela UFMG em cotutela com a Université D’Avignon (França). Professora da Graduação e Professora Permanente Do Programa De Pós-Graduação Em Direito Da Escola Superior Dom Helder Câmara - Mestrado Em Direito Ambiental E Desenvolvimento Sustentável.

\section{Resumo}

Este artigo objetiva analisar o contexto de um novo programa comunitário europeu de ação ambiental e o papel da universidade na visão da União Europeia no tocante à educação ambiental confrontando-a à Política Nacional de Educação Ambiental Brasileira. Destacando a adequação dos Países Europeus, em especial a Espanha aos regulamentos e diretivas da União relativas ao meio ambiente cuja proteção, conservação e preservação se tornam um dever de todos para assegurar o desenvolvimento sustentável para as geraçóes presentes e futuras. A imperatividade desta preocupação se torna um verdadeiro desafio, pois a proteçáo do meio ambiente abre o ser humano a um mundo de desafios e de oportunidades, tendo as aspiraçôes mais profundas e nobres de viver em um ambiente sadio e equilibrado, ou seja, o ambiente em que prevalece a qualidade de vida. Para esse fim, adotar-se-á o método dedutivo abarcado na pesquisa bibliográfica e descritiva, considerando a situação problema sobre o papel da universidade em uma Europa do conhecimento na era da educação ambiental. 


\section{Palavras-chave}

Educação Ambiental; União Europeia; Comissão; Meio Ambiente; Brasil; Política Nacional de Educação Ambiental.

\section{Resumen}

Este artículo se propone analizar el contexto de un nuevo programa comunitario de acción ambiental y el rol de la universidad en la opinión de la Unión Europea en materia de educación ambiental comparándola con la Política Nacional de Educación Ambiental de Brasil. Destacando la adecuación de los países europeos, especialmente Espańa a los reglamentos y directivas de la UE relacionadas con el medio ambiente, cuya protección, conservación y preservación convertido en el deber de todos para asegurar un desarrollo sostenible para las generaciones presentes y futuras. El imperativo de esta preocupación se han convertido en un verdadero reto porque la protección del medio ambiente se abre al ser humano a un mundo los desafíos y oportunidades, con las aspiraciones más profundas y nobles de vivir en un medio ambiente sano y equilibrado, es decir, el medio ambiente que prevalece en la calidad de vida. Para ello, vamos adoptar se el método deductivo abarcado en la investigación bibliográfica y descriptiva, teniendo en cuenta la situación del problema acerca del rol de las universidades en una Europa del conocimiento en la época de la educación ambiental.

\section{Palabras clave}

Educación Ambiental; Unión Europea; Comisión; Medio Ambiente; Brasil; Política Nacional de Educación Ambiental.

\section{Introdução}

Procura-se abordar neste artigo o contexto de um novo programa comunitário de ação ambiental e o papel da universidade na visão da União Europeia no tocante à educação ambiental à luz das Conferências Internacionais e, ao mesmo tempo, analisar o processo educativo brasileiro e a implementação do Programa Nacional de Educação Ambiental para melhor proteger e conservar o meio ambiente, bem de uso comum do povo, essencial à sadia qualidade de vida e sua sustentabilidade, como bem destaca o art. 225, da Constituição da República de 1988.

Em tempo do capitalismo liberal, a universidade era vista "o lugar privilegiado da produção de alta cultura e conhecimento científico avançado”, como ressalta Boaventura de Sousa Santos (2008, p. 193) e gozava de grande prestígio social quanto à qualidade de ensino dispensando para a formação das elites. Diante das "pressóes e transformaçóes 
oriunda da sociedade, a universidade cujos fins principais eram a investigação, o ensino e a prestação de serviços" (SANTOS, 2008, p.188) torna-se palco de multiplicidade de funçôes e de contradiçóes que a levaria a uma crise de hegemonia dentro do sistema educativo.

As dificuldades hoje comumente reconhecidas de planificar adequadamente o sistema educativo em função das necessidades previsíveis da mão-de-obra no mercado de trabalho dos próximos anos e, portanto, o deficiente desempenho das funçôes econômicas e instrumentais da universidade náo impedem esta, antes pelo contrário, de desempenhar adequadamente funções sociais e simbólicas, como, por exemplo, a função de inculcar nos estudantes valores positivos perante o trabalho e perante a organizaçáo econômica e social de produçáo, regras de comportamento que facilitem a inserção social das trajectórias [sic] pessoais, formas de sociabilidade e redes de interconhecimento que acompanham os estudantes muito depois da universidade e muito para além do mercado de trabalho, interpretaçóes da realidade que tornam consensuais os modelos dominantes de desenvolvimento e os sistemas sociais e políticos que os suportam. (SANTOS, 2008, p. 191)

É importante analisar a questão da educação ambiental a partir do programa comunitário de ação ambiental oriundo da Comissão Europeia e, em seguida, abordar os desafios e as perspectivas quanto à importância da formação universitária assentada na aquisição de conhecimentos técnicos e científicos, de noções jurídicas mescladas com competências baseadas em curriculares multidisciplinares como requer a educação ambiental de maneira integrada aos programas educacionais desenvolvidos.

Estudar o meio ambiente, nas universidades, é fundamental; porém não se pode olvidar que, há décadas, as universidades eram vistas espaços de centralidade cultural e de formação de elites. Tal modelo, nos dizeres de Boaventura de Sousa Santos (2008, p. 191) vai levar as universidades a entrarem em crise de hegemonia manifestada na crise de legitimidade e na crise institucional, colocando em causa "a exclusividade dos conhecimentos que a universidade produz e transmite".

Hoje em dia, procura-se resgatar a responsabilidade social das universidades e seu papel na construção de um Estado socioambiental com múltiplos desafios quanto à conservação do meio ambiente e à construção de um futuro sustentável. Não se trata mais de sonhos, menos ainda de utopia, mas de uma realidade vigente e urgente porque o meio ambiente se faz presente na Agenda Política dos Estados, inclusive dos Estados membros da União Europeia, objeto do presente artigo quanto ao seu Programa Comunitário de Ação Ambiental com os 04 domínios prioritários estabelecidos no sexto programa de ação para o meio ambiente, a saber: as mudanças climáticas, a biodiversidade, o meio ambiente e a saúde, e a gestão sustentável dos recursos e dos resíduos sólidos. 
Para esse fim, adotar-se-á o método dedutivo abarcado na pesquisa bibliográfica e descritiva, considerando a situação problema sobre o papel da universidade em uma Europa do conhecimento na era da educação ambiental.

\section{Educação Ambiental no Direito Internacional: Breve Análise}

Já no fim da década de 60, a degradação ambiental era um novo problema social que emergia em quase todos os países industrializados. Com isso, a visão de mundo pelo ser humano existente até então, entra em crise, o que leva à construção de uma nova visão, que tem suas bases na teoria da Antiguidade, segundo a qual o ser humano assume e demonstra sua interdependência com o meio ambiente e passa a exercer uma cidadania universal com base inclusive na Carta de Direitos Humanos da ONU.

Neste contexto, surgem os interesses dos atores políticos e institucionais tradicionais acerca do meio ambiente, bem como o surgimento e fortalecimento de movimentos civis organizados. Tudo isso culmina na progressiva elaboração de políticas ambientais para enfrentar o problema da excessiva e descontrolada degradação ambiental que levou à extinção de várias espécies e ao surgimento de várias doenças e modificações climáticas no planeta. Destaca-se nesta época o chamado "Grupo de Roma” formado por cientistas, industriários e empresários que esboçaram uma preocupação ambiental e financiaram o trabalho "Limites do Crescimento" ou "Relatório Meadows".

O Relatório Meadows ou "Limites do Crescimento", produzido no fim da década de 70 pelo MIT e financiado pelo Clube de Roma, vai iniciar uma discussão, na comunidade internacional, sobre os problemas surgidos no planeta pela degradação da natureza pelo ser humano que conduzira à criação da noção de meio ambiente. Esta discussão incentivou a organização de movimentos sociais que acabam por sensibilizar os governos dos países, que em 1972, realizam em Estocolmo, de 5 a 16 de junho, a Conferência da ONU sobre o Ambiente Humana, mais conhecida como Convenção de Estocolmo. Nela foram discutidos e criados princípios gerais que serviriam de orientação aos Estados para instituírem políticas e leis de preservaçáo e melhoria do meio ambiente, bem como o reconhecimento da simbiose entre natureza e seres humanos. Surgindo, assim, o primeiro Marco Internacional do Direito Ambiental que trará entre seus princípios e recomendações a proposição de criar uma educação ambiental para efetivar a proteção deste meio ambiente. Segundo Dias (2003, p. 79) “a recomendação no96 da conferencia reconhecia o desenvolvimento da educação ambiental como o elemento crítico para o combate à crise ambiental" e dentre os princípios da Declaração da Convenção de Estocolmo (ONU, 1972), o $19^{\circ}$ apresenta

É indispensável um esforço para a educação em questôes ambientais, dirigida tanto às geraçóes jovens como aos adultos e que preste a devida 
atenção ao setor da populaçáo menos privilegiado, para fundamentar as bases de uma opiniấo pública bem informada, e de uma conduta dos indivíduos, das empresas e das coletividades inspirada no sentido de sua responsabilidade sobre a proteção e melhoramento do meio ambiente em toda sua dimensão humana[...]

Com base no principio 19 e na recomendaçáo 96, ocorre em 1975 em Belgrado (Iugoslávia) o Encontro Internacional sobre educação ambiental promovido pela UNESCO. Neste encontro, estudiosos apresentavam a necessidade de uma nova lógica para o ensino, inserindo a questão ambiental, já propondo que este deveria ter uma nova logica distinta da compartimentalista cartesiana, devendo ser interdisciplinar e holística. Mas defendem que esta não deveria, também, ser globalmente estabelecida, já que deveria estar integrada aos interesses de cada país, região. A educação ambiental deveria estar inserida na vida dos indivíduos não apenas enquanto estes fossem estudantes, mas sim de forma contínua. Todos estes preceitos foram configurados no texto do Programa Internacional de Educaçáo Ambiental (PIEA), texto final do encontro. E, também, propuseram um encontro que ocorreria em dois anos daquela data, para discutir mais profundamente e globalmente como realizar tudo isso.

Ocorre, então, em 1977 na cidade de Tbilisi, na Geórgia (ex URSS), a primeira Conferência Intergovernamental sobre educação ambiental organizada pela UNESCO e pelo PNUMA, que reuniu especialistas de todo mundo para analisar as propostas que foram feitas em encontros sub regionais promovidos pela ONU. Para o desenvolvimento da educação ambiental foi recomendado que se considerassem todos os aspectos da questão ambiental, bem como aquela se desenvolvesse de forma articulada entre as disciplinas. (DIAS, 2003). Demonstrando, portanto, a visão integrada do meio ambiente de forma que indivíduos e coletividade compreendesse a complexidade do meio ambiente e adquirisse conhecimentos e valores num processo contínuo. Segundo Moradillo e Oki (2004) A declaração produzida nesta reunião trouxe as linhas básicas iniciais que proporcionariam diretrizes para os países efetivarem a Educação Ambiental. Estas linhas foram aperfeiçoadas em publicaçóes posteriores da UNESCO em 1985,1986, 1988 e 1989. Ao fim acordaram em realizar em 10 anos outro encontro, que foi realizado em Moscou em 1987 para analisar as conquistas e problemas da implementação do plano estabelecido em Tbilisi e propor soluções.

A terceira conferência foi realizada em agosto de 1987 em Moscou, e segundo Moradillo e Oki (2004) destacou-se das demais por criar um quadro teórico-metodológico que possibilitou a concretização da Educação Ambiental, já que possibilitou a reorientação do processo educacional e criou um plano de ação para efetivar a educação ambiental ao longo da década de 90. Este documento tem especial importância porque é nele que se estabelece a busca em efetivar a dimensão ambiental na educação universitária, como forma 
prioritária, tanto para a formação de educadores ambientais, como de profissionais das diversas áreas do conhecimento que tivessem em sua base o conhecimento das questóes ambientais para aplicação em suas área de atuação. Tendo dado prioridade, para efetivar esta ação, a desenvolvimento de sensibilização para as autoridades acadêmicas, desenvolvimento de programas de estudo, formação de professores e cooperação institucional.

O outro grande evento da educação ambiental ocorreu em Thessaloniki em 1997 para dar continuidade ao plano de Moscou. E o último dos eventos sobre o tema ocorreu em 2007 em Ahmedahbad na Índia, dando continuidade aos pressupostos de Tbilisi e interagindo com o a busca do Desenvolvimento Sustentável.

O principal documento de todos e que dá origem a uma ação coordenada da educação ambiental será a Declaração de Tbilisi, que tem por objetivos propor aos Estados como objetivo conduzir os indivíduos e grupos sociais a adquirir consciência e sensibilidade para o ambiente e problemas conexos, bem como incentivar experiências para compreensão destes, efetivando a ativa participação comunitária na melhoria da proteçáo do meio ambiente, e na solução de problemas ambientais. (DIAS, 2003).

Tbilisi traz propóe também os princípios norteadores da educação ambiental que vão servir de base para a proposição das políticas educacionais tanto através das convençóes e encontros posteriores sobre o tema quanto nos países, sendo:

1) considerar o ambiente em sua totalidade;

2) ser um processo contínuo ao longo da vida, iniciando-se na pré-escola e prosseguindo por todos os estágios seguintes, formais, não formais e informais;

3) ser interdisciplinar em sua abordagem, utilizando o conteúdo específico de cada disciplina de forma a demonstrar sua inserção no todo da ciência, de forma equilibrada e holística;

4) incentivar a inserção e analise dos aspectos ambientais em planos para o desenvolvimento, que devem buscar ser sustentáveis

5) focar em questóes ambientais potenciais e atuais sem ignorar a perspectiva histórica;

6) promover e demonstrar o valor e necessidade da cooperação, local, nacional e internacional, na prevenção e solução de problemas ambientais;

7) examinar as questóes ambientais a partir dos pontos de vista locais, nacionais, regionais, e internacionais, para que indivíduos recebam informaçóes sobre as condiçóes ambientais em outras áreas geográficas;

8) capacitar estudantes a terem um papel no planejamento de suas experiências de aprendizagem e dar oportunidade de tomarem decisóes e aceitarem as consequências que vem destas; 
9) relacionar, para todas as idades, sensibilidade ambiental, conhecimentos, habilidades de solução de problemas e valores;

10) ajudar aprendizes a descobrirem sintomas e causas reais de problemas ambientais;

11) enfatizar a complexidade dos problemas ambientais, e a necessidade de se desenvolver consciência crítica e habilidades de solução de problemas, sempre pensando em uma perspectiva de interação ambiental;

12) utilizar diversos ambientes de aprendizagem e uma ampla coleção de métodos educacionais, para que se possa ensinar, aprender sobre, e aprender do ambiente, com devida atenção em atividades práticas e experiências originais. (ARAUJO, 2007)

A estes, com a Convenção Rio/92, se acresceu a importância de ensinar e propiciar o Desenvolvimento sustentável, princípio basilar das Ciências Ambientais, a partir de então. Este surge com a publicação do Relatório Brundtland em 1987 - que teve seu projeto proposto na Convenção de Estocolmo de 1972 - que deste momento em diante e passa a ter papel essencial também nas questóes de educação ambiental.

Convenção realizada no Rio de Janeiro em 1992 trouxe, em seu texto, também a preocupação com a participação comunitária como um dos objetivos e princípios centrais da luta pela proteção do meio ambiente no mundo. Assim, não poderia ficar de fora a discussão sobre a educação ambiental, central para a formação destes cidadãos de forma a garantir sua efetiva participação para alcançar o desenvolvimento sustentável.

Esta inovação se dá, em especial, pelo período de escrita e discussóes da Declaração, que se realiza já na conformação do Estado Democrático de Direito no mundo em substituição ao Estado Social. Como sabido, o Estado Social pressupóe uma atuação mais incisiva e centrada nos poderes públicos tutelando a sociedade de forma a garantir os direitos dos cidadãos, enquanto o Estado Democrático de Direto pressupóe a real atuação dos cidadãos em conjunto com o Estado, de forma que agora eles participem efetivamente dos desígnios do país para que seus anseios sejam atendidos. (CUSTODIO, 2013)

Isso aparece claramente no Princípio 10 da Declaração Rio/92 (ONU, 1992) que define:

O melhor modo de tratar as questôes ambientais é com a participação de todos os cidadãos interessados, em vários níveis. No plano nacional, toda pessoa deverá ter acesso adequado à informação sobre o ambiente de que dispõem as autoridades públicas, incluída a informação sobre os materiais e as atividades que oferecem perigo a suas comunidades, assim como a oportunidade de participar dos processos de adoção de decisóes. 
Os Estados deverão facilitar e fomentar a sensibilização e a participação do público, colocando a informação à disposição de todos.[...].

Bem como nos outros documentos produzidos durante o encontro no Rio de Janeiro em 1992, como se percebe, no Tratado de Educação Ambiental para Sociedades Sustentáveis e Responsabilidade Global (TEASS) - proposto no Fórum das Organizações Não Governamentais e Movimentos Sociais, evento paralelo da ECO/92; e na Agenda 21, em seu capítulo 36 que corroborou com as proposiçôes de Tbilisi/77. (DIAS, 2003)

Percebe-se, como define a Agenda 21 (ONU, 1992a) que "O ensino tem fundamental importância na promoção do desenvolvimento sustentável e para aumentar a capacidade do povo para abordar questóes de meio ambiente e desenvolvimento", e a compreensão social da real relação entre sociedade e meio ambiente, demonstrando a simbiose que se vive. Neste ponto, a educação ambiental é essencial conduzindo a formação dos indivíduos que se compreendem como cidadãos globais.

\subsection{Conceito de Educação Ambiental}

A educação é um direito básico dos seres humanos, desde o estabelecimento do Estado Social, e foi reafirmado na Carta de Direitos Humanos da ONU de 1948 e em outros documentos internacionais posteriormente.

A educação, segundo Helita Barreira Custódio (2005, p.12) é

Ação de criar, educar, ensinar, instruir ou desenvolver as faculdades físicas, religiosas, morais, artísticas, intelectuais, profissionais da pessoa humana de todas as idades e condiçôes sociais, desde o ensino elementar ou fundamental (precedido ou não da pré escola) ao ensino médio e técnico até o ensino superior (com a indispensável vinculaçáo ao permanente desenvolvimento mediante pesquisa jurídico cientifico tecnológica) dentro da escola ou da universidade, alem da educaçáo continua, por todos os meios institucionais de comunicação, de experiência, de cursos de pós graduação ( mestrado, doutorado), especialização, aperfeiçoamento, ou fora da escola ou da universidade, em continua investigaçáo, descoberta ou defesa à pratica da verdade, visando ao bem estar de todos [...] direito fundamental, inalienável e inviolável de todas as pessoas individual, social ou coletiva e publicamente consideradas, direta ou indiretamente relacionado tanto com o reconhecimento de sua própria dignidade humana e da dignidade da pessoa humana em todas as idades e condiçóes sociais com a conscientização de seus próprios direitos, de seus deveres, de suas obrigaçóes e das respectivas responsabilidades individuais, familiares, sociais, nacionais e internacionais. 
A educação ambiental, entretanto é algo recente. Datando dos primórdios da década de 70 do século XX, após a mobilização em torno da questão ambiental surgida no fim da década de 60 e início da década de 70, que culminou na Convenção de Estocolmo de 1972.

O conceito de educação ambiental, aplicado no Brasil, é dado pela Lei 9795/99, que em consonância com a Constituição Federal de 1988, em seu artigo primeiro que define

Art. 1o Entendem-se por educação ambiental os processos por meio dos quais o indivíduo e a coletividade constroem valores sociais, conhecimentos, habilidades, atitudes e competências voltadas para a conservação do meio ambiente, bem de uso comum do povo, essencial à sadia qualidade de vida e sua sustentabilidade (MEDAUAR, 2013, p.453).

pelo conceito já se percebe a característica transindividual da construção da educação ambiental que pode ser classificada em três tipos:

a) A educaçáo informal, que apesar de não ser tratada pela lei de forma direta, aparece nos tratados internacionais como ponto importante ligado a participação social e deveres dos cidadãos enquanto membros de uma sociedade democrática, construída sobre a égide do Estado Democrático de Direito. Pode ser conceituada como as açóes para efetivar a educação ambiental fora do ambiente escolar.

b) A náo formal legalmente conceituada no art.13 da mesma lei como "as ações e práticas educativas voltadas à sensibilização da coletividade sobre as questóes ambientais e à sua organização e participação na defesa da qualidade do meio ambiente". (MEDAUAR, 2013, p.455)

c) E por fim, A formal que é a educação escolar, definida pela lei 9795/99 como

Art. $9^{\circ}$ Entende-se por educação ambiental na educação escolar a desenvolvida no âmbito dos currículos das instituiçôes de ensino públicas e privadas [...] Art. 10. A educação ambiental será desenvolvida como uma prática educativa integrada, contínua e permanente em todos os níveis e modalidades do ensino formal. (MEDAUAR, 2013, p.455)

Este trabalho concentra especial atenção a educação formal, especialmente nos cursos de nível superior e. Dar-se-á especial atenção ao papel na formação a partir destes do educador ambiental essencial para uma efetivação real dos preceitos de educação ambiental que garantem a formação e efetividade de cidadania ambiental como transparece na Constituição Federal de 1988 - CF/88.

Está educação passa pelos vários tipos de relaçôes entre as ciências, disciplinas e saberes sendo sua base, portanto, transdisciplinar, como toda Ciência Ambiental. 


\subsection{Educação Ambiental e Transdisciplinaridade}

Pensada, inicialmente, por Descartes e outros criadores da Ciência na modernidade, a divisão rígida do estudo do mundo em áreas do conhecimento estanques foi motivada pela crença de que apenas a especialização levaria ao desenvolvimento cientifico. Para eles a especialização dos profissionais e do estudo dos objetos em visóes compartimentada em áreas possibilitariam um estudo mais aprofundado de cada um dos objetos do mundo, $\mathrm{e}$ por fim do mundo como um todo. Partiam do pressuposto que, ao dividir o estudo era com dividir uma maçá, onde o estudo do todo era impossibilitado, mas ao retirar uma fatia e estudá-la refletiriam o todo.

Hoje, entretanto, especialização e a especialidade chegaram a tal ponto que se perdeu a perspectiva do todo do conhecimento ou estudo do mundo ou mesmo onde o objeto de estudo de cada área estanque se insere. Isso levou à busca da análise deste todo novamente e à integração destes olhares sobre o mesmo objeto, ideia defendida pela transdisciplinaridade, que busca ainda ampliar a visão deste todo para além da ciência moderna e normatizada.

Outro ponto importante em relação a especialização é a busca incessante da generalização. Isso faz com que o objeto de estudo perca sua personalidade para se encaixar em uma generalidade de características, apresentando seu pertencimento a um todo semelhante que tem pontos comuns. Tal fato leva, assim, a sua simplificação para estudo, que o insere em uma das categorias conhecidas somente pela ciência. Isso exclui os não pertencentes à área, criando uma barreira ou limite aos outros indivíduos. Segundo Morin (2005, p.60), "vivemos a época da especialização com a obsessão pela simplificação", o que nos leva a ignorar a identidade e a singularidade dos atos, fatos, seres, e sem percebermos, ao distanciamento da realidade -pleonástica- complexa e a criação da realidade generalizada, onde segundo Morin (2005), a ciência ignora o ser humano comum e este fica ignorante sobre a ciência.

Para compreender a transdisciplinaridade, inicialmente deve-se entender o que ela não é. Ser transdisciplinar não é ser multi ou interdisciplinar e menos ainda ser holístico.

Assim deve-se compreender que:

a) Multidisciplinaridade é uma gama de disciplinas que são propostas simultaneamente, mas sem fazer aparecer às relaçóes que podem existir entre elas, formando sistema de um só nível e de objetivos múltiplos onde não há nenhuma cooperação entre estas disciplinas.(ROHDE, 1996)

b) Pluridisciplinaridade é a justaposição de diversas disciplinas situadas geralmente no mesmo nível hierárquico e agrupadas de modo a fazer aparecer as relaçôes existentes entre elas. Formam um sistema de um só nível e de objetivos 
múltiplos, havendo cooperação, mas sem coordenação entre as disciplinas. (ROHDE, 1996)

c) interdisciplinaridade é forma um sistema onde há coordenação e cooperação entre as diversas disciplinas conexas. (GUSTIN; DIAS, 2001)

Já ter um a visão holística do objeto é criar um conceito dominante a partir do qual as disciplinas devem congregar.

O transdisciplinar vai além, pois ele congrega as várias visóes disciplinares do objeto, mas náo exclui os saberes a respeito dele, congregando conhecimentos e saber a respeito do objeto analisado, em conjunto. Todos dão sua contribuição em relação ao estudo do objeto formando uma perspectiva não generalista, mas ampla deste. Para compreender isso devemos compreender a diferença entre conhecimento e saber.

O conhecimento vem da experiência científica. Somente pode ser construído pelo olhar do cientista sobre o objeto, onde este mede, analisa, descreve, se distância e demonstra o que o objeto é. O saber, ao contrário, demonstra a relação do indivíduo com o objeto de estudo, suas peculiaridades ante a generalização, o como o indivíduo ou indivíduos veem o objeto de estudo no mundo, fugindo da simplificação e trabalhando a singularidade, tal qual um romance, que segundo Morin (2005, p.57) "mostra vida cotidiana, mas seres singulares, uma vida onde cada um joga em vários papéis sociais seja em casa, no trabalho com amigos etc". Assim mostra a interdependência do todo, para formar o objeto real com sua complexidade inerente e inserção no todo dos objetos do mundo.

A transdisciplinaridade, segundo Castillo (2010), é um dos ideais de educação ambiental, onde os objetivos de compreensão do meio ambiente. Este, somente pode ser compreendido, quando tratado através do todo das áreas de conhecimento e formando associações com os saberes.

Somente através de uma perspectiva transdisciplinar na educação ambiental é possível cumprir e promover os novos valores e condutas que devem ser ambientalmente corretos, que tem como princípio norteador a ética nas relações sociais.

A Educação Ambiental é uma das possibilidades de reconstrução multifacetada não cartesiana do saber humano, constituindo-se num saber construído socialmente e caracteristicamente multidisciplinar na estrutura, interdisciplinar na linguagem e transdisciplinar na sua ação. Ela deve visar a transformação do educando através do desenvolvimento de novos valores, hábitos, posturas, condutas e atos na relação com o ambiente considerado em toda a sua complexidade. (MORADILLO; OKI, 2004, p.334) 
E completam "O papel da escola, dentro de uma perspectiva política não ingênua, é o de criar espaços através de seus atores e autores sociais no sentido da desalienação dos indivíduos, diante do conhecimento fragmentado e destituído de significado para suas açóes sociais." (MORADILLO; OKI, 2004, p.334)

A Educação ambiental em nível universitário é a mais importante nesta função, pois, com base no pensamento e conhecimento desenvolvido nos ensinos fundamental e médio sobre o meio ambiente, ela conduz em nível superior à efetiva analise e pensamento crítico sobre o tema efetivando a transdisciplinaridade para aplicação da educação ambiental na realidade fática e vivida nas profissóes destes graduandos.

\section{0 Papel das Universidades da Visão Europeia e a Educação Ambiental}

Desde os tempos remotos, tanto na antiga Grécia e na Roma antiga como nos tempos atuais, a educação e a formação do indivíduo, sempre foi uma preocupação das sociedades em que pertence, salvo o papel daqueles que eram tratados como escravos, apesar de existirem alguns casos isolados sobre a formação intelectual de escravos a pedido de seus senhores.

Em tempo de modernidade e pós-modernidade, cobra-se mais das universidades por serem vistas pela sociedade como fonte de inspiração, de saber e de conhecimento. São o receptáculo da sabedoria e o farol das culturas e centros sócio-transformadores suscetíveis de quebrar os paradigmas antigos. Não seria diferente em tempos atuais para que as universidades sejam lugares de tomada de consciência da visão global do meio ambiente, das relaçóes entre o ser humano e a natureza, agregando valores e atitudes responsáveis para a transformação da sociedade em seu processo de desenvolvimento sustentável.

Para Boaventura de Sousa Santos (2008, p.187), "Um pouco por todo o lado, a universidade confronta-se com uma situação complexa: são-lhe feitas exigências cada vez maiores por parte da sociedade ao mesmo tempo em que se tornam cada vez mais restritivas as políticas de financiamento das suas actividades [sic] por parte do Estado”.

Tratam-se, contudo, de desafios que vêm dos dois lados: a sociedade e o Estado. Antes, consideravam-se as universidades como lugar de busca da verdade, assim como destacava Karl Jaspers (1965) citado por Boaventura de Sousa (2008), tendo por objetivo principal a investigação e, sendo "um centro de cultura, disponível para a educação do homem no seu todo [...]" Visa-se, nas universidades, a formação integral do indivíduo assentada, segundo Santos (2008, p. 188) nos "três fins principais" a saber, a investigação, o ensino e a prestação de serviços.

Apesar de a inflexão ser, em si mesma, significativa e de ser dado no sentido atrofiamento da dimensão cultural da universidade e do privilegiamento do seu conteúdo utilitário, produtivista, foi sobretudo ao nível 
das políticas universitárias concretas que a unicidade dos fins abstractos (sic) explodiu numa multiplicidade de funçôes por vezes contraditórias entre si. A explosão das funcçóes foi, afinal, o correlato da explosão da universidade, do aumento dramática da população estudantil e do corpo docente, da proliferação das universidades, da expansão do ensino. (SOUSA, 2008, p. 187)

Ao citar Moscati (1983), Boaventura de Sousa Santos (2008) destaca as contradiçóes que existem entre a produção de alta cultura e de conhecimentos exemplares necessários à formação das elites e a produção de padrôes culturais médios e de conhecimentos úteis para as tarefas de transformação social.

No entender de Boaventura de Sousa Santos (2008, p. 190), a universidade sofre uma tripla crise. A primeira é a crise de hegemonia, "na medida em que a sua incapacidade para desempenhar cabalmente funçôes contraditórias leva os grupos sociais mais atingidos pelo seu défice funcional ou o Estado em nome deles a procurar meios alternativos de atingir os seus objectivos [ sic].” Na segunda tradição entre hierarquização e democratização, Santos (2008, p.190) vê nela a segunda crise que sofre a universidade que é a crise de legitimidade. Para ele, "A universidade sofre uma crise de legitimidade na medida em que se torna socialmente visível à falência dos objectivos colectivamente [sic] assumidos".

A terceira crise ocorre, nos dizeres de Santos (2008, p. 190), "entre autonomia institucional e produtividade social." Trata-se da crise institucional que se manifesta "sempre que uma dada condição social estável e auto-sustentada deixa de poder garantir os pressupostos que asseguram a sua reprodução.” Nesse caso, salienta Santos (2008, p. 190), “A universidade sofre uma crise institucional na medida em que a sua especificidade organizativa é posta em causa e se lhe pretende impor modelos organizativos vigentes noutras instituiçóes tidas por mais eficientes." Na realidade, espera-se da universidade, apesar de "o deficiente desempenho das funções econômicas e instrumentais",

a função de inculcar nos estudantes, valores positivos perante o trabalho e perante a organização econômica e social de produção, regras de comportamento que facilitem a inserção social das trajectórias pessoais, formas de sociabilidade e redes de interconhecimento que acompanham os estudantes muito depois da universidade e muito para além do mercado de trabalho, interpretaçôes da realidade que tornam consensuais os modelos dominantes de desenvolvimento e os sistemas sociais e políticos que os suportam.(SANTOS, 2008, p. 191)

Assim, comprova a essencialidade da Universidade na cultura e formação dos indivíduos enquanto cidadãos. 


\subsection{Universidade e Conhecimento}

A universidade vista como lugar de transmissão da ciência, da cultura, da investigação e do ensino entra em crise nos anos sessenta devido à multiplicidade de funçóes, de tensóes e contradiçóes em seu processo educativo. Para Boaventura de Sousa Santos(2008, p. 190)

a universidade sofre uma crise de hegemonia na medida em que a sua incapacidade para desempenhar cabalmente funçôes contraditórias leva os grupos sociais mais atingidos pelo seu défice funcional ou o Estado em nome deles a procurar meios alternativos de atingir os seus objetivos.

Tal crise de hegemonia se manifesta na crise de legitimidade "na medida em que se torna socialmente visível a falência dos objectivos [sic] colectivamente assumidos.” (SANTOS, 2008, p. 190) Entende-se, nesse sentido que, "há uma crise de legitimidade sempre que uma dada condição social deixa de ser consensualmente aceite." (SANTOS,2008, p. 190)

Além da crise de hegemonia oriunda também da contradição entre a hierarquização dos saberes especializados e as exigências da democratização e da igualdade de oportunidades, Santos menciona também uma crise institucional entre "autonomia institucional e produtividade social.”( SANTOS, 2008, p. 190) Nos seus dizeres,

Há uma crise institucional sempre que uma dada condição social estável e auto-sustentada deixa de poder garantir os pressupostos que asseguram a sua reprodução. A universidade sofre uma crise institucional na medida em que a sua especificidade organizativa é posta em causa e se lhe pretende impor modelos organizativos vigentes noutras instituições tidas por mais eficientes. (SANTOS, 2008, p. 190)

A universidade deve ser o lugar favorável e privilegiado para favorecer a inserção social e a efetividade do princípio da igualdade de oportunidades e não de exclusão social e de "continuação, consolidação e até de aprofundamento das desigualdades sociais" (SANTOS, 2008, p. 191), ou seja, de perpetuar um sistema socialmente injusto e incoerente com os objetivos da própria universidade de lutar pelos direitos sociais enquanto espaço de democratização e de cultura. É sabido que antes, a universidade visava a produção de alta cultura e conhecimento avançado, como bem assinala Santos (2008, p. 193), o que é fruto do capitalismo liberal e que vai acarretar a crise hegemônica com as dicotomias baseadas em alta cultura x cultura popular, educação x trabalho e teoria x prática.

Observa-se, nesse caso, a passagem do elitismo para a massificação da universidade, entre a alta cultura e a cultura de massas, com a consequência de degradação da produção cultural na esmagadora maioria das universidades como sublinha Santos (2008, p.194) 
Para Pedro Goergen (2003, p. 102), “ a universidade, para além das tarefas de ensino e pesquisa e extensão, não pode esquecer-se de sua responsabilidade formadora das geraçôes de acadêmicos." Trata-se de a universidade assumir a sua responsabilidade social, conscientizando-se e familiarizando-se "com os grandes temas e problemas que envolvem e preocupam o ser humano na atualidade." (GOERGEN, 2003, p. 102) Nota-se que o dever formativo, nesse caso, encontra-se umbilicalmente ligado ao compromisso social da universidade. A preocupação do processo formativo dos acadêmicos deve levar em conta a formação dos acadêmicos com relação aos importantes temas atuais, indo além do conceito que domina as atividades de pesquisa e ensino, o "de racionalidade instrumental, técnico e operacional”. (GOERGEN, 2003, p. 102)

Um dos grandes temas de atualidade no século XXI é, sem dúvida, o do meio ambiente, de sua preservação e proteção dentre do espírito do Estocolmo e demais Convençóes Internacionais sobre o meio ambiente. A formação para defendê-lo exige ter em mente a "premência de proteger e melhorar o meio ambiente" (ONU, 1972), pois, a contribuição do mundo acadêmico, segundo Gilberto Luiz Alves (2003, p. 219), "precisa ser dimensionada no âmbito de uma sociedade concreta, a sociedade capitalista, que produz, sobretudo, as diferenças sociais”.

Muito embora a universidade seja vista como um lugar de conhecimento e saberes, não se pode olvidar a responsabilidade social como compromisso "com o desenvolvimento equilibrado e integral do indivíduo e da humanidade como um todo, na relação dos homens entre si e com seu meio." (GOERGEN, 2003, p. 105) Por ser, justamente, uma instituição social, a universidade deve ter como preocupação a desenvolvimento equilibrado e integral do ser humano e do meio ambiente, como bem observa Goergen (2003, p. 105).

A crise da modernidade que é também uma "crise atual da razão" segundo Horkheimer citado por Gorgen (2003, p. 106), e, pode-se emendar dizendo que ela é também existencial e, ao mesmo tempo de valores e princípios em um mundo dilacerado pelas guerras e pela exploração desenfreada dos recursos naturais e da degradação do meio ambiente.

Faz-se necessário uma educação ambiental nas universidades para que elas não se tornam instituiçóes de risco em uma sociedade de risco, como bem preconiza Ulrick Becker $^{1}$ (1986) ao considerar a individualização e a globalização da atual sociedade, sua modernização, seus problemas ambientais e suas desigualdades sociais.

1 Ulrich Becker foi um dos pensadores mais influentes da época e um dos sociólogos mais citados nos meios acadêmicos com a publicação e tradução de seu livro "Sociedade de Risco" em mais de 30 idiomas. Morreu aos 70 anos em 01 de janeiro de 2015. 


\subsection{Universidade e Educação Ambiental}

A Conferência Intergovernamental sobre Educação Ambiental de Tbilisi deixa bem claro que "a educação ambiental é o resultado de uma reorientação e articulação de diversas disciplinas e experiências educativas que facilitam a percepção integrada do meio ambiente, tornando possível uma ação mais racional e capaz de responder às necessidades sociais.” TBILISI, 1977)

Desse modo, convém salientar que, no âmbito europeu, especificamente, da União Europeia, existe Programas de Ação Comunitário para o Ambiente nos quais são descritas a política ambiental, o programa de ação, a proteçáo do ambiente e demais assuntos sobre consumo, saúde, mudanças climáticas, energias renováveis.

$\mathrm{O}$ contexto do novo programa relativo ao ambiente visa à qualidade de vida que requer um ambiente sadio e, os cidadãos europeus exigem um grau de proteção do meio ambiente, tendo em vista o desenvolvimento econômico futuro e o crescimento da prosperidade e considerando a capacidade do planeta a assegurar a demanda dos recursos.

Na Uniáo Europeia, segundo o sexto Programa de Ação comunitária para o ambiente, denominado, "Meio Ambiente 2010: nosso futuro, nossa escolha", apresentado pela Comissão, 30 anos de política ambiental conduziram a um sistema global de controles ambientais. O 5o Programa de Ação (1992-1997) em matéria ambiental e desenvolvimento sustentável, intitulado "Para um desenvolvimento sustentável" tomou novas medidas e manifestou a vontade mais larga de integrar a preocupaçôes ecológicas em outras políticas. $^{2}$

O 60 Programa define, de maneira, mais eficaz, conforme o comunicado, os objetivos e prioridades ambientais que são partes integrantes da estratégia da União Europeia no tocante ao desenvolvimento sustentável. Tal Programa delineia as grandes prioridades e os objetivos principais da política ambiental dos 05 a 10 próximos anos.

De modo geral, o 60 Programa da UE, em matéria ambiental, se resume, em 04 dimensóes de ação prioritárias, a saber: a) os esforços de atenuação das mudanças climáticas, cujo objetivo visa a estabilizar as concentraçôes atmosféricas de gás estufa ao nível que não provocará as variaçôes artificiais do clima sobre a terra; b) a natura e a biodiversidade - proteger um recurso único - cujo objetivo é proteger e restaurar o funcionamento dos sistemas naturais, e acabar com o empobrecimento da biodiversidade na UE e no mundo. Proteger os solos da erosão e da poluição; c) meio ambiente e saúde, tendo por objetivo

2 Vide Communication de la Commission au Conseil, au Parlement Européen, au Comité économiqueet social et au Comité des Régions - sur le sixième programme communautaire d'action pourl'environnement "Environnement 2010: notre avenir, notre choix" - sixième programme pour l'environnement. Disponível em: http://eur-lex.europa.eu/legal-content/PT/TXT/HTML/?uri=CELEX:52001DC0031\&from=FR Acesso em: 28 maio 2015. 
atingir uma qualidade de meio ambiente na qual os níveis de contaminantes artificiais, incluindo os diferentes tipos de radiação, não produzam incidências ou riscos notáveis para a saúde das pessoas; d) o uso sustentável dos recursos naturais e gestão sustentável dos resíduos sólidos, zelando para que o consumo dos recursos renováveis e não renováveis não ultrapassa o que o ambiente pode suportar. ${ }^{3}$

Como se pode observar neste $6^{\circ}$ Comunicado da Comissão, os recursos do planeta, especialmente, os recursos renováveis tais quais, o solo, a água, o ar e a madeira, estão sujeito á uma forte pressão por parte da sociedade humana. (UNION EUROPÉENNE, 2010) Considerando tal urgência, faz-se necessário definir estratégias suscetíveis de assegurar o uso sustentável dos recursos. É nesse contexto que se torna imperativa a educação ambiental nas universidades europeias, partindo do respeito e da efetividade dos objetivos e das finalidades e princípios contidos nas Declarações das Conferências Internacionais sobre a Educação Ambiental e, ao mesmo, tempo implementar nos meios acadêmicos as decisóes das políticas ambientais oriundas da União Europeia que requerem "conhecimentos científicos sólidos e análises econômicas, fundadas nas informações e dados confiáveis sobre o ambiente[...]" (UNION EUROPÉENNE, 2001, s/p), conforme o supracitado Comunicado da Comissão de 2010.

Nessa lógica de ideias, o alargamento das políticas ambientais deve alcançar as universidades para que ela endossa o discurso ambiental em seu processo educativo através de uma formação articulada em diversas disciplinas (estudos multidisciplinares) abarcada em conhecimentos técnicos científicos, em noções jurídicas e competências sociológicas, antropológicas e filosóficas. Trata-se de uma abordagem integrada devido ao caráter multidisciplinar da educação ambiental.

É importante, nesse caso, adotar estratégias nas universidades com relação ao meio ambiente e desenvolvimento sustentável, para dar à formação um caráter mais científico e técnico para uma gestão do ambiente, sem olvidar a necessidade de fornecer bases multidisciplinares aos estudantes que sejam sólidas e que "favoreçam o desenvolvimento de comportamentos compatíveis com a preservação e melhoria desse meio ambiente", como ressalta a Recomendação no 1 da Conferência Intergovernamental sobre Educação Ambiental de Tbilisi (1977).

Considerando as universidades uma fonte de oportunidades, mas também de grandes desafios, indaga-se diante das políticas ambientais da Uniâo Europeia, qual seria seu papel numa Europa da promoção do desenvolvimento sustentável, sabendo das dificuldades que ela enfrentam tanto no âmbito nacional como regional relativas à sua real inserção na dimensão europeia?

3 Idem. 
O Comunicado da Comissáo de 05 de fevereiro de 2003 sobre o papel das universidades na Europa do conhecimento [COM (2003) 58 final - Non publié au journal officiel], além apresentar algumas dificuldades enfrentadas pelas universidades quanto aos recursos humanos como financeiros, aponta alguns desafios europeus aos quais estão confrontadas: a) o aumento da demanda na formação superior; b) a internationalização da educação e da pesquisa; c) o desenvolvimento de uma cooperação estreita e eficaz entre s universidades e a indústria; d) a multiplicação de lugares de produção de conhecimentos; d) a reorganização de conhecimento; e) a emergência de novos desafios. (UNION EUROPÉENNE, 2003) ${ }^{4}$

Como exemplo da educação ambiental e formação construída no contesto europeu , como imperativo estabelecido pela Comissão europeia, apresentar-se-á um breve histórico da construção da Educação Ambiental na Espanha.

\subsection{Educação Ambiental na Espanha}

Após a Conferencia de Tbilisi em 1977, a Espanha inicia um processo de analise para implementar Educação ambiental, e começa a realizar jornadas de estudos entre educadores ambientais para entender como aplicar os preceitos e diretrizes da Conferência. Cepeda (2002) divide a historia da educação ambiental da Espanha em três etapas:

a) A Etapa Inicial, onde cada região autônoma tem sua organização e bases, sendo um período marcado pela diversidade e coincide com a transição democrática e abertura ao associacionismo e participação importante do movimento ecologista. "Finalmente, devemos ressaltar o papel de pioneiros, grupos, empresas e sindicatos de educação ambiental, que foram cruciais para seu impulso inicial e posterior desenvolvimento no nosso país” (CEPEDA, 2002, s/p).

As primeiras "Jornadas Nacionais sobre Educação ambiental" ocorrem em 1983 em Barcelona, as segundas em 1987 em Valsain (Segóvia). Nesta, em especial foram feitas analises da educação ambiental, trazendo novas linhas de trabalho. Estas jornadas servirão de base para inaugurar o Centro Nacional de Educação Ambiental (CENEAM) vinculada ao Ministério da educação - hoje é ente autônomo- em Valsain. (CEPEDA, 2002)

As segundas jornadas tiveram papel importante na construção da Educação ambiental espanhola, pois, tornaram vários de seus grupos de trabalhos em permanentes de forma a sistematizar a organização para incentivar a educação ambiental sendo os principais os grupos sobre:

4 Vide Communication de la Commission Du 5 février 2003 - Le role des universités dans l'Europe de la connaissance [COM (2003) 58 final - Non publié au Journal officiel]. Disponívelem: http://eurlex.europa.eu/legal-content/FR/TXT/HTML/?uri=URISERV:c11067\&from=FR Acesso em: 28 maio 2015. 
- sobre Programas institucionais de Educação Ambiental,

- sobre Educação Ambiental em Áreas Protegidas,

- $\quad$ sobre introdução da Educação Ambiental no Sistema Educativo

- e sobre Avaliação de Programas e Educação Ambiental

O trabalho destes grupos culmina no livro "Seminários Permanentes de Educação Ambiental" publicado em 1996 pelo Ministério de Meio Ambiente (CEPEDA, 2002).

b) A fase de institucionalizaçáo, ainda nos anos 80 , que acompanha a efetivação das autonomias e coincidem com as primeiras jornadas da educaçáo ambiental em (Sitges, Barcelona em 1983) passando pelas outras jornadas.

Em 1988 é realizado o "Seminário sobre Educação Ambiental para a implantação desta disciplina no Sistema Educativo.” em Navas del Marqués (Ávila) organizado pela comissão da UNESCO na Espanha que tinha por base as intençóes da resolução do Conselho da Europa (Resolução 88/CI177/03-24/05/88) e que culminou na criação da LOGSE (Ley Orgánica General del Sistema Educativo), a partir de 1990. Ela incorpora a educação ambiental, como tema transversal, dentro do currículo e traz o reconhecimento oficial do professor de educação ambiental como profissão.

c) A etapa do repensar crítico, já nos anos 90, que conduz a exigência de critérios de qualidade dos programas e atividades, destacando a necessidade de uma educação ambiental que chegue a toda a sociedade e atente aos princípios de sustentabilidade, vendo a educação ambiental como um instrumento de enfrentando da crise sócio ambiental. Este tem como evento principal as terceiras jornadas nacionais sobre educação ambiental, que ocorreram em 1998 em Pamplona, organizada pelo Ministério do Meio ambiente. Destas jornadas surge o rascunho do que em 1990 se configuraria no "Libro Blanco de la Educación Ambiental en España” (MINISTERIO DE MEDIO AMBIENTE, 1999).que teve ampla participação de profissionais e especialistas em educação ambiental em um foro aberto organizado em cinco mesas coordenadas pelas diferentes regióes autonômicas com participação pela internet e vários aportes de todos os interessados.. Ele traz o consenso, devido à sua forma democrática de criação, trazendo recomendaçóes, açóes e iniciativas a serem realizadas,

Se quer dar um novo impulso à educação ambiental, com foco em determinados aspectos que podem ser particularmente relevante nos anos seguintes: a) maior atenção aos programas educativos aos fatores sociais (culturais, políticos e econômicos), a prevenção de problemas e o debate sobre alternativas sustentáveis. b) Impacto na mudança de valores e comportamentos, além dos aspectos de sensibilização e informação ambiental. c) progressão gradual da educação ambiental para toda a comunidade e nos diferentes contextos de vida (profissionais, educacionais, 
recreativas). d) inter-coordenação administrativa em todos os âmbitos e a coordenação entre os setores público e privado, com especial atenção para criação de redes e a promoção das já existentes, para melhorar a eficácia e eficiência dos planos e programas de ação. (CEPEDA, 2002, p.132)

Como recomendaçóes têm-se:

1. A educação ambiental deve ser uma referência fundamental no planejamento e na gestáo dos centros de ensino.

2. Melhorar a formação ambiental dos professores, tanto dos futuros professores quanto daqueles que estáo atualmente em serviço.

3. A valoração da quantidade e qualidade dos recursos existentes e melhor a eficiência.

4. A colaboração entre os centros de ensino e destes com a sociedade de entorno. (MINISTERIO DE MEDIO AMBIENTE, 1999).

Neste sentido, percebe-se que a educação e formação sobre meio ambiente na Espanha cumpre os requisitos e recomendaçóes da Comissão europeia relativas ao 6 programa comunitário de ação para o meio ambiente intitulada “ Meio Ambiente 2010: Nosso Futuro, Nossa Escolha”.

\section{A Educação Ambiental no Brasil}

No Brasil, apesar do artigo de Krasilchik, na década de 80, ser o pioneiro na descrição da evolução da Educação Ambiental no Brasil (MORADILLO;OKI, 2004), as bases para a formação de uma política pública de educação ambiental tem inicio na Lei 6938/81 que cria a PONAMA- Política Nacional de Meio Ambiente. Ainda em vigor, esta propóe a Política Nacional de Meio ambiente no Brasil. Para tanto tem como base a educação da população para a formação de cidadãos conscientes sobre a questão ambiental, como transparece no art. 20, inciso X "educação ambiental a todos os níveis de ensino, inclusive a educaçáo da comunidade, objetivando capacitá-la para participação ativa na defesa do meio ambiente" (MEDAUAR, 2013, p.917).

Sete anos depois a CF/88 constitucionaliza o tema. Será a CF/88 que trará a obrigatoriedade constitucional de instituir uma educação voltada para a conscientização da importância de proteção do meio ambiente e da importância da participação da sociedade, o que transparece especialmente nos artigos 205, 210, 215, 216 e 225 inciso VI. Como defende Beatriz Souza Costa (2014), todos os brasileiros e estrangeiros residentes no Brasil têm parte de responsabilidade com um mundo melhor para geraçóes futuras.

Seu cumprimento se dará pela Lei 9597/99 que implementará a PNEA - Política Nacional de Educação Ambiental, - será a primeira lei sobre educação ambiental da 
América Latina (layrargues,2012)- ,Lei esta regulamentada pelo Decreto 4281/2002. A lei obriga a inserção da educação ambiental na educação formal com configuração interdisciplinar, como claramente explicita no art. $8^{\circ} \$ 3^{\circ}$ inciso I. Tal perspectiva se dá inicialmente, mas vai se desenvolvendo para buscar uma transdisciplinaridade.

Em âmbito federal vários órgãos estiveram envolvidos na implementação da educação ambiental, através de vários programas como o PRONEA (Programa Nacional de Educação Ambiental), DEA (Diretrizes de Educação Ambiental), o PEPEA (Programa de Estudos e Pesquisa em Educação Ambiental), bem como a inserção da educação ambiental na Lei de Diretrizes e Bases da Educação Brasileira (MORADILLO; OKI, 2004).

Além da Lei e sua regulamentação, segundo Layrargues (2012) houve a criação de vários marcos regulatórios para garantir a efetividade da lei, através da gestão publica. Entre eles o autor cita

a resolução 422/2010 do Conselho Nacional do Meio Ambiente, que estabelece as diretrizes para as campanhas, açóes e projetos em educação ambiental, a Nota Técnica 01/2010 do Ibama, que estabelece as diretrizes para os programas de educação ambiental no âmbito do licenciamento ambiental do petróleo e gás, e a "Estratégia nacional de comunicação e educação ambiental em Unidades de Conservação", lançada pelo Ministério do Meio Ambiente em 2011.” (LAYRARGUES, 2012, s/p)

Chegou-se inclusive a se pensar na criação de um Sistema Nacional de Educação Ambiental, que buscaria dar um salto de qualidade na articulação institucional entre os atores e instituiçóes que lidam com a educação ambiental não só entre as esferas de governo, mas deste com a sociedade civil, para potencializar a sinergia e complementaridade neste processo educativo que se espera ser contínuo e permanente. (LAYRARGUES, 2012)

A lei do PNEA incentivou a educação não formal (art.13) e informal (art.3o), demonstrando claramente a importância de todas as formas de educação para a realização da cidadania ambiental.

A educação formal é ponto essencial para que o indivíduo participe dessa defesa do meio ambiente e para que este se enxergue como parte do problema e da solução, concretizando o princípio da participação comunitária. Somente assim poderá ser garantida a efetivação dos os princípios básicos do Direito Ambiental que buscam proteger legalmente o meio ambiente - Princípio do ambiente ecologicamente equilibrado como direito fundamental da pessoa humana, Princípio do acesso equitativo ao meio ambiente, Princípio da precaução, Princípio do desenvolvimento sustentável e Princípio da prevenção.

Nesta perspectiva deve ser lembrada a teoria pedagógica trazida por Vygotsky. 
Nas décadas de 20 e 30 do século XX, surge a corrente da psicologia educacional chamada sócio-interacionista, criada pelo russo Lev Semovich Vygotsky, que desenvolveu seu trabalho na Rússia leninista, e criou tal corrente baseada nos preceitos da teoria de Engels e Marx, especialmente na dialética e no materialismo histórico.

Atualmente, seu trabalho vem, cada vez mais, ganhando importância e interpretaçôes, especialmente no campo da educação infantil, onde participou de várias discussôes teóricas, destacando-se pelas críticas que fez à teoria de seu contemporâneo, Piaget ${ }^{5}$.

Vygotsky traz uma contribuição importante para a compreensão da formação do conceito, quando esclarece como a palavra adquire significação conceitual, explicando que, para análise da palavra, deve-se dividir o significado em dois componentes. Um deles é o significado propriamente dito, que "[...] refere-se ao sistema de relaçóes objetivas que se formou no processo de desenvolvimento da palavra, consistindo num núcleo relativamente estável de compreensão da palavra, compartilhado por todas as pessoas que a utilizam" (OLIVEIRA, 2001, p. 50), ou seja, a generalização que possibilita a compreensão do elemento, possibilitada pela educação formal. E o outro é o sentido que se refere ao significado da palavra para cada indivíduo, composto por relaçóes que dizem respeito ao contexto de uso da palavra e às vivências afetivas do indivíduo, isto é, a individualização do elemento filtrado por sua realidade. Assim, todo e qualquer pensamento é uma generalização, que é fruto do real associado ao cultural, num contexto em que a palavra evolui, pois, além de seu significado, ela tem o sentido que lhe dá valor.

É nessa modificação e com o desenvolvimento cultural que o ser humano, enquanto ser vivo transforma-se em social por meio de um processo de internalização de comportamentos culturais desenvolvidos na sua sociedade.

Assim, a criação e a internalização de um conceito, por um indivíduo, não é algo mecânico e passivo como as teorias clássicas tentam estabelecer, nem individualista como faz transparecer a teoria de Piaget, mas é fruto de uma complexa operação, na qual a palavra é o mediador indispensável e central na construção desse processo. A mera criação e memorização de uma determinada palavra e sua relação com um objeto não forma um conceito, pois, se assim fosse, estaria sendo ignorado o pano de fundo em que se desenvolve essa relação, que é a construção histórica e a dinâmica social. Reafirmando, assim, a importância da educação ambiental formal para a compreensão do mundo pelo sujeito.

A formação do conceito surge da relação pessoal do sujeito com o objeto a ser conceituado, interpretada e mediada pela ideia cultural-social sobre o mesmo objeto no

5 Ele acreditava que a estrutura dos estágios descrita por Piaget seja correta, porém difere na concepção de sua dinâmica evolutiva, pois, Piaget defende que a estruturação do organismo precede o desenvolvimento, para os sociointeracionistas é o próprio processo de aprendizagem que gera e promove o desenvolvimento das estruturas mentais superiores (VYGOTSKY,1991). 
ambiente em que ele vive e no qual ele absorve a forma de ver o mundo, processo sempre mediado por palavras e interação social, possibilitados pela educação formal que traz a generalização, reconhecida sócio-culturalmente, pela sociedade em que ele se insere. Desse modo, o conceito surge quando a linguagem perpetrada pela sociedade interage com o mundo interior (seu eu). Adverte-se que, para que o conceito seja gerado, não é suficiente apenas a interação, é necessário que o meio social, o ambiente, estimule o intelecto e faça sempre novas exigências, obrigando o indivíduo a perseguir seus objetivos. Por isso, o pensamento náo consegue atingir o desenvolvimento necessário para absorver, pensar, avaliar e desenvolver o conceito. Ou seja, depende de mais que ligações associativas; dependem do instigar, do impulso, da necessidade imposta pelo meio ambiente. Através dessa demonstração, destaca-se que os indivíduos não absorvem simplesmente a forma de pensar que a sociedade quer transmitir, pois isso é impossível. O que a sociedade faz é dar o significado acabado daquele elemento para que ele forme seu complexo e crie sua generalização, sempre estimulado pelo ambiente. Demonstrando a importância da transdisciplinaridade na educação ambiental, mesmo em âmbito formal.

Com essa abordagem, o autor apresenta os dois tipos de conceitos que devem interagir, sempre que possível, para formar o conceito generalizado, quais sejam, o espontâneo e o científico. O conceito espontâneo "tem origem numa situação de confronto com uma situação concreta” (VYGOTSKY, 1991, p.73) e os conceitos científicos implicam logo de início uma atitude mediada relativamente ao seu objeto.

$\mathrm{Na}$ falta de conceito cientifico para maturação, a aprendizagem inicia com a imitação para chegar ao aprendizado, mesmo na educação.

Assim, o conceito pode até surgir da imitação, mas sua internalização nos indivíduos e mesmo na sociedade passa pela relação do pensamento com a linguagem, que é fruto do desenvolvimento histórico da consciência humana. Nesse sentido é que se entende a importância do educar para o olhar dos indivíduos comuns, para preparar as geraçóes atuais e as futuras para o cuidado com a natureza, o meio ambiente, conscientização da proteção do meio ambiente para ser capaz de não apenas dar valor, mas auxiliar a sociedade com açóes efetivas e mobilizadoras de e para proteção. (CUSTÓDIO, 2014) Tudo isso apenas é possível se o sujeito a que se direciona tiver os conceitos generalizados internalizados, pois assim pode criticar e/ ou aprimora-los através das informaçôes, entretanto, o contrário não é possível.

A educação ambiental formal no período entre a Rio 92 e a Rio+20, teve uma expansão considerável no ensino fundamental brasileiro, (notadamente entre 2001 e 2004), atingindo a universalização do acesso à ela na escola e reduzindo as disparidades existentes entre os estados. (LAYRARGUES, 2012)

Mas a preocupação efetiva ficou nessas etapas de ensino. A graduação, apesar de fazer parte do ensino, pouco foi instigado a inserir a educação ambiental em seus currículos, 
apesar de ter determinação legal. Isso se dá ainda pela organização cartesiana da organização do ensino no Brasil, feita de forma bem compartimentalizada, inclusive nas áreas, divididas em departamentos cartesianamente divididos que não dialogam de forma a compreender a simbiose das áreas e sua inter-relação obrigatória. Isso segundo Layrargues (2012), pode estar ligado a não internalização cultural na escola brasileira dos Parâmetros Curriculares Nacionais, criados em 1997, que a CAPES a duras penas vem tentando impor, inclusive pelas avaliações das faculdades. Seu principal elemento é o ENADE, que traz muito das questóes ambientais em seu bojo em todas as áreas de graduação que os alunos se submetem à prova. Outro ponto trazido por Layrargues (2012), é a demora da aprovação da proposta das Diretrizes Curriculares Nacionais para a Educação Ambiental, pelo Conselho Nacional de Educação.

No entanto, vale salientar, que os dados "de 2004 indicaram a universalização da educação ambiental no ensino fundamental, com expressivo numero de escolas 94,95\%- que declaram ter educação ambiental de alguma forma, por inserção temática no currículo, em projetos ou até mesmo, uma minoria, em disciplina especifica. Em termos de atendimento, existiam em 2001 cerca de 25,3 milhóes de crianças com acesso a educação ambiental, sendo que, em 2004, esse total subiu para 32,3 milhóes" ( MELLO, TRAJBER, 2007, p.18)

Assim, percebe-se que apesar da formação distinta da base da educação ambiental no Brasil, ela caminha a passos largos dentro das recomendaçóes internacionais e se aproxima das propostas da Uniáo Europeia.

\section{Conclusões}

Tendo a Educação Ambiental iniciado com a proposição na Convenção de Estocolmo (1972) e progredido através de Convençôes próprias como Tbilisi (1977), Moscou (1990) e Thessaloníki (1997), hoje tem papel fundamental para a conservação e proteção do meio ambiente, sendo componente primordial e imprescindível no processo formativo do individuo e da coletividade. Na atualidade a educação ambiental é essencial para compreensão dos seres humanos sobre a garantia do bem comum em prol da sadia qualidade de vida e da sustentabilidade.

Dai a importância das universidades em participar das discussóes juntamente com a sociedade de forma a construir a transdisciplinaridade na analise da economia de mercado, propondo novas perspectivas e soluçóes para a real aplicação do desenvolvimento sustentável e efetivar a proteção do meio ambiente, agregando os valores, conhecimentos, habilidades e atitudes e competências voltadas para o meio ambiente enquanto bem de uso comum dos povos. 
Procurou-se abordar nesse trabalho que, apesar das diferenças sociais mundiais, busca-se hoje um caminho conjunto de realização da educação ambiental em todos os Estados, de forma a garantir que todos participem como cidadãos globais. Nisso as universidades são lugares ou espaços privilegiados não apenas de discussóes, mas de abertura para a implementaçáo das politicas publicas desempenhando para tanto um papel decisivo na consecução dos objetivos estratégicos traçados nos Documentos Internacionais, propiciando a efetivação do preceito das responsabilidades comuns mas desiguais na garantia do bem estar social comum , uma vez que o planeta é nosso único futuro e portanto todos devem cumprir seu papel, ou seja, há uma responsabilidade de solidariedade planetária.

Assim sendo propôe se que os Estados devem fazer cada vez mais investimentos nas Universidades para garantir a eficácia e a maximização da efetivação da educação ambiental nestas, assegurando o conhecimento cientifico técnico, pesquisas e noçóes jurídicas fundamentais para preservação do meio ambiente e a construção dos saberes sociais.

\section{Referências}

ALVES, Gilberto Luiz. Tendências da Educação no início do Terceiro Milênio para a construção de uma Sociedade mais democrática. In: LOMBARDI, José Claudinei. Temas de pesquisa em educação. Campinas: Autores Associados, 2003, pp. 219232.

ARAÚJO, Thiago Cássio d'Ávila. Principais Marcos Históricos Mundiais da Educação Ambiental. Disponível em <http://noticias.ambientebrasil.com.br/artigos/2007/09/11/33350-principais-marcos-historicos-mundiais-da-educacao-ambiental.html>. Acessado em 11 de novembro de 2012.

BRASIL.. CONSELHO NACIONAL DE EDUCAÇÃO. Resolução no 2 , de 15 de junho de 2012. Estabelece as Diretrizes Curriculares Nacionais para a Educação Ambiental. Disponível em: < http://conferenciainfanto.mec.gov.br/images/pdf/diretrizes.pdf> Acesso em: 28 maio 2015.

. Lei no 3.833, de 27 de março de 2006. DODF de 04.04.2006. Dispóe sobre a educação ambiental, institui a Política de Educação Ambiental do Distrito federal, cria o Programa de Educação Ambiental do Distrito Federal,complementa a Lei federal no 9.795/99 no âmbito do Distrito federal, e dá outras providências. Disponível em: <http://www.ibram.df.gov.br/informacoes/educacao-ambiental/ibram-e-a -educacao-ambiental.html> Acesso em: 28 maio 2015.

CASTILLO, Róger Martínez. La importancia de la educación ambiental ante la problemática actual. In:Revista Electrónica Educare, vol. XIV, núm. 1, enero-junio, 2010, pp. 97-111 disponível em Disponivel em <http://www.redalyc.org/articulo. oa? $\mathrm{id}=194114419010>$ Acesso em 15/05/2015. 
CEPEDA, J. Samuel Sánchez. Diagnóstico Y Perspectivas De La Educación Ambientalen Extremadura. Vol1. Tese (Programa de Doctorado:"Enseńanza de las Ciencias Experimentales y las Matemáticas) -Departamento de Didáctica de las Ciencias Experimentales y de las Matemáticas da Facultad De Formación Del Profesorado Da Universidad De Extremadura. Cárceres, 2002. Disponível em < http://dialnet. unirioja.es/servlet/tesis?codigo=331> Acesso em 15/05/2015.

COSTA, Beatriz Souza. A construção do sujeito constitucional ambiental. In Veredas do Direito. v. 8, n. 15 (2011) Disponível em <http://www.domhelder.edu.br/revista/ index.php/veredas/article/view/163> Acesso em 15/05/2015.

CUSTÓDIO, Helita Barreira. Direito Ambiental e Questóes Jurídicas Relevantes. Campinas, SP: Millenium Editora, 2005.

CUSTODIO, Maraluce Maria. D. Benta E As Estripulias De Emília Em "A Reforma Da Natureza” E A Educação Ambiental Informal In: NOGUEIRA, Bernardo G.B.; SILVA, Ramon Mapa da . Direito e Literatura: Por que devemos escrever narrativas? Belo Horizonte: Arraes Editores, 2013. Pags 44-60.

Introduçáo ao Direito de Paisagem: Contribuiçóes ao seu reconhecimento como ciência no Brasil. Rio de Janeiro: Lumen Iuris, 2014.

DIAS, Edna Cardozo. Manual de Direito Ambiental.2aed .Belo Horizonte: Mandamentos, 2003.

GOERGEN, Pedro. Universidade e Responsabilidade Social. In: LOMBARDI, José Claudinei. Temas de pesquisa em educaçáo. Campinas: Autores Associados, 2003, pp. 101-122.

GRANZIERA, Maria Luiza Machado. Direito Ambiental. 3 ed. São Paulo: Atlas, 2014.

GUSTIN, Miracy Barbosa de Souza. Curso de Iniciaçáo à pesquisa jurídica e a elaboraçáo de projetos: (re)pensando a pesquisa jurídica: teoria e pratica. $3^{\text {a }}$ ed ver atual e aum. Belo Horizonte: UFMG/NIEPE, 2001.

LAYRARGUES, Philippe Pomier. Educação ambiental no Brasil: o que mudou nos vinte anos entre a Rio 92 e a Rio+20 In: ComCiência no.136 Campinas mar/2012. Disponível em < http://www.comciencia.br/comciencia/?section=8\&edicao=75\&id=938> Acesso em 15/05/2015.

LOMBARDI, José Claudinei (Org.) Temas de pesquisa em educação. Campinas-SP: Autores Associados, 2003: HISTEDBR; Caçador, SC: UnC, 2003. - (Coleção educação contemporânea).

. (Org.) Globalizaçáo, pós-modernidade e educação: história, filosofia e temas transversais. Campinas-SP: Autores Associados: HISTEDBR; Caçador, SC: UnC, 2001. - (Coleção educação contemporânea) 
MEADOWS, Donella H. et al. Limites do Crescimento: Um Relatório para o Projeto do Clube de Roma sobre o Dilema da Humanidade. São Paulo: perspectiva, 1973.

MEDAUAR, Odete (org.). Constituição Federal, Coletânea de Legislação de Direito Ambiental. 13a ed. rev. atual. e ampl. São Paulo: Editora Revista dos Tribunais, 2013. RT Mini-códigos.

MELLO, Soraia Silva de; TRAJBER, Rachel.(Coord) Vamos cuidar do Brasil : conceitos e práticas em educação ambiental na escola. Brasília: Ministério da Educação, Coordenação Geral de Educação Ambiental: Ministério do Meio Ambiente, Departamento de Educação Ambiental: UNESCO, 2007. 248p.

MINISTERIO DO MEIO AMBIENTE ( ESPAÑA). Libro Blanco: de la Educación ambiental en España en Pocas Palavras. Madri: Secretaría General de Medio Ambiente, 1999. Disponível em <http:/www.magrama.gob.es/es/ceneam/recursos/ documentos/pocas_tcm7-13555.pdf > Acesso em 15/05/2015.

MORADILLO, Edilson Fortuna de; OKI, Maria da Conceição Marinho. Educação Ambiental Na Universidade: Construindo Possibilidades In: Quim. Nova, Vol. 27, No. 2, 332-336, 2004 Disponível em <http://www.scielo.br/pdf/qn/v27n2/19284. pdf> Acesso em 15/05/2015.

MORIN, Edgar. Introduçáo ao pensamento complexo. tradução: LISBOA, Eliane. Porto Alegre: Sulina, 2005.

OLIVEIRA, Maria Kohl de. Vygotsky: Aprendizado E Desenvolvimento - Um Processo Sócio-Histórico, 4a edição, São Paulo Editora Scipione, 2001.

ONU. Agenda 21 Global.1992. Disponível em< http://www.mma.gov.br/responsabilidade-socioambiental/agenda-21/agenda-21-global>. Acessado em 11 de novembro de 2012 .

. Declaraçáo de Estocolmo Sobre o Ambiente Humano. Estocolmo, 1972. Disponível em <http://www.silex.com.br/leis/normas/estocolmo.htm>. Acessado em 11 de novembro de 2012.

. Declaraçáo do Rio Sobre Meio Ambiente e Desenvolvimento. Rio de Janeiro, 1992 Disponível em <http://pactoglobalcreapr.files.wordpress.com/2010/10/declaracao-do-rio-sobre-meio-ambiente.pdf>. Acessado em 11 de novembro de 2012.

PEREIRA, Elisabete Monteiro de Aguiar. A Universidade nos Paradimas da modernidade e da pós-modernidade. In: LOMBARDI, José Claudinei. Temas de pesquisa em educaçáo. Campinas: Autores Associados, 2003, pp. 124-140.

PRESTES, Vanêsca Buzelato (Org.) Temas de direito urbano. Belo Horizonte: Fórum, 2006. 
ROHDE, Geraldo Mario. Epistemologia ambiental: uma abordagem filosófico-cientifica sobre a efetuação humana alopoteia. Porto alegre: EDIPUCRS, 1996, p.7-107.

SANTOS, Boaventura de Sousa. Pela mão de Alice: o social e o político na pós-modernidade. 12 ed. São Paulo: Cortez, 2008.

SEIFFERT, Maria Elizabete Bernardini. Gestão Ambiental: Instrumentos, Esferas de Ação e Educação Ambiental. 3 ed. São Paulo: Editora Atlas, 2014.

SIMIONI. Rafael Lazzarotto. Direito Ambiental. Curitiba: Juruá, 2006.

UNION EUROPÉENNE. Communication de la Commission au Conseil, au parlement Européen, au Comité Économique et Social et au Comité des Régions sur le sixième Programme Communautaire $d$ 'action pour l'Environnement "Environnement 2010: notre avenir, notre choix" - sixième programme d'action pour 1'environnement/*COM/2001/0031 final/ Disponível em:< http://eur-lex. europa.eu/legal-content/PT/TXT/HTML/?uri=CELEX:52001DC0031\&from=FR> Acesso em: 28 maio 2015.

Communication de la Commission Du 5 février 2003 - Le rôle des universités dans 1'Europe de la connaissance [COM (2003) 58 final - Non publié au Journal officiel]. Disponível em: <http://eur-lex.europa.eu/legal-content/FR/TXT/ HTML/?uri=URISERV:c11067\&from=FR> Acesso em: 28 maio 2015.

VYGOTSKY, Lev Semenovich. A formaçáo social da mente: Psicologia e Pedagogia: O desenvolvimento dos processos psicológicos superiores, Livraria Martins Fontes Editora Ltda., 4a edição, São Paulo - SP, 1991.

. Pensamento e Linguagem. Tradução: MORES, Rev. Ridendo Castigat, 2009. Disponível em <http://www.ebooksbrasil.org/eLibris/vigo.html> Acesso em: $15 / 11 / 2010$. 